\title{
POSSIBILIDADES E DESAFIOS DA CRIANÇA AUTISTA NA ESCOLA
}

Ademir Henrique Manfré, Beatriz Moreira Frutuoso, Marcia Aparecida de Lima Santos, Tauana Rafaela Neiva

Universidade do Oeste Paulista - UNOESTE, Curso de Pedagogia, Presidente Prudente, SP. E-mail: bia.ladydark@hotmail.com

\section{RESUMO}

O presente trabalho tem como objetivo geral apresentar, discutir e refletir sobre a temática da criança autista e a formação docente na educação escolar. A metodologia escolhida para este estudo se baseia em uma pesquisa bibliográfica que buscou investigar o objeto proposto nos principais periódicos educacionais brasileiros. São eles: a) Revista Educação e Sociedade; b) Revista Educação Especial; c) Revista Brasileira de Estudos Pedagógicos; d) Revista Educação e Pesquisa; e) Revista Interface; f) Cadernos de Pesquisa em Educação. Desse modo, foram analisadas as orientações de diferentes autores do campo educacional, tornando possível a compreensão da problemática exposta. Assim, centramos a nossa análise na questão da criança autista no ensino regular e a formação dos docentes para uma educação inclusiva. Em relação à formação docente, a pesquisa apontou que essa deve ser pautada pela reflexão constante, pela capacidade de enfrentar os desafios de uma educação comprometida com a inclusão.

Palavras-chave: Autismo. Educação. Inclusão Escolar. Formação docente.

\section{POSSIBILITIES AND CHALLENGES OF THE AUTISTIC CHILD AT SCHOOL}

\begin{abstract}
The present work has the general objective to present, discuss and reflect on the autistic child and the role of the teacher in school education. The methodology chosen for this study is a qualitative approach and is based on a bibliographical research that sought to investigate the object proposed in the main Brazilian educational periodicals. They are: a) Education and Society Magazine; b) Special Education Magazine; c) Brazilian Journal of Pedagogical Studies; d) Education and Research Journal; e) Interface Magazine; f) Cadernos de Pesquisa em Educação. In this way, the orientations of different authors of the educational field were analyzed, making possible the understanding of the problematic presented here. Thus, we focus our analysis on the issue of autistic children in regular education and the training of teachers for an inclusive education. Regarding teacher training, it should be guided by reflection, the ability to identify and face the challenges of a longterm education project, and not immediately.
\end{abstract}

Keywords: Autism. Education. School inclusion. Teacher training. 


\section{APRESENTAÇÃO: situando o debate}

A pesquisa aqui apresentada intitulada "Possibilidades e desafios da criança autista na escola", tem como objetivo geral apresentar uma discussão a respeito do tema TEA e formação de professores. Sustenta-se em um estudo bibliográfico pautado em autores como: Frazão e Porto (1999), Mantoan (2008).

Os educadores têm enfrentado dificuldades em seu cotidiano na sala de aula pelo fato de se depararem com diversas situações, entre elas com os alunos com necessidades educacionais especiais.

Surge então o intuito de refletir sobre os desafios encontrados por educadores que se deparam com a tarefa de incluir crianças autistas no processo de escolarização. Observa-se, nas últimas décadas, e mais especificamente a partir da Declaração de Salamanca (1994), a preocupação com a dificuldade de inclusão de crianças com necessidades educacionais especiais nos anos iniciais do ensino fundamental.

A inclusão escolar se consolida a partir da inserção de todos na escola, sem distinção. É uma educação voltada para todos, de forma que qualquer aluno que dela faça parte independente ou não de ter necessidades educacionais especiais tenha condição de conhecer, aprender e viver num ambiente livre de preconceitos. Inclusão não pode significar adequação ou normatização, tendo em vista um encaixar de alunos numa maioria privilegiada, mas uma conduta de participação, com o conviver que respeite as diferenças e não reincidi-las (SALGADO, 2012).

De acordo com Frazão e Porto (1999), a inclusão no ambiente escolar consiste em possibilitar à criança um desenvolvimento dentro de seus limites pessoais, e não de padrões impostos socialmente; acreditar que a criança com necessidades especiais é capaz de uma aprendizagem rica e construtiva.

Em relação aos objetivos da escola, Mantoan (1997) destaca a valorização de papéis sociais que pressupõem a igualdade de valor entre as pessoas, independentemente das características ou diferenças, físicas ou mentais que possam apresentar. Nesse contexto, a educação de pessoas com necessidades educacionais especiais é vista como algo mais do que a simples oportunidade de participação deste indivíduo no meio produtivo do capital, pois passa a enfatizar tanto o desenvolvimento das habilidades e talentos pessoais, como dos papéis sociais.

No que se refere à temática do $T^{1} A^{1}$, sabemos que as crianças autistas precisam de motivação e organização para aprender (XAVIER, 2002). Em relação às atividades, devem ser práticas, pois, dessa forma, favorecem um melhor entendimento do conteúdo escolar. A interação de crianças autistas nem sempre foi assunto tratado com grandes critérios, tendo em vista que a inclusão escolar está engatinhando nesse sentido para uma relevante conquista social, e é um passo importante no tratamento da problemática e da aprendizagem do autista.

\section{METODOLOGIA: os caminhos trilhados}

Dentre os caminhos metodológicos pensados para este estudo, inicialmente, esta pesquisa partiu de um estudo bibliográfico em que foram analisadas as orientações de diferentes autores da Educação, tornando possível a compreensão da problemática aqui exposta. De acordo com Fonseca (2002, p. 32):

A pesquisa bibliográfica é feita a partir do levantamento de referências teóricas já analisadas, e publicadas por meios escritos e eletrônicos, como livros, artigos científicos, páginas de web sites. Qualquer trabalho científico inicia-se com uma pesquisa bibliográfica, que permite ao pesquisador conhecer o que já se estudou sobre o assunto. Existem, porém, pesquisas científicas que se baseiam unicamente na pesquisa bibliográfica, procurando referências teóricas publicadas com o objetivo de recolher

\footnotetext{
${ }^{1}$ No CID-10, o autismo aparece como SínDROME DE ASPERGER. Já o DSM V (2013), traz o termo TRANSTORNO DO ESPECTRO AUTISTA (TEA), conceituação utilizada por nós.
} 
informações ou conhecimentos prévios sobre o problema a respeito do qual se procura a resposta.

Assim, realizamos uma pesquisa bibliográfica com levantamento de artigos publicados nos principais periódicos científicos na área de Educação no Brasil, no período de 2005 a 2015, que abordaram as temáticas do TEA e formação de professores.

Para tanto, a nossa pesquisa organizou-se em duas etapas:

1. Primeira etapa: levantamento de artigos referentes à temática de estudo. Essa etapa possibilitou uma visão mais ampla sobre a produção teórica nesse campo do conhecimento. Os periódicos selecionados para este estudo são os que seguem abaixo:

a) Revista Educação e Sociedade;

b) Revista Educação Especial;

c) Revista Brasileira de Estudos Pedagógicos;

d) Revista Educação e Pesquisa;

e) Revista Interface;

f) Cadernos de Pesquisa em Educação.

2. Segunda etapa: apresentar os resultados da análise dos artigos.

Nessa segunda etapa, tivemos como intuito:

a) verificar que metodologias têm sido utilizadas (tipos de estudos, métodos, técnicas e populações analisadas);

b) verificar como o TEA e a formação de professores têm sido analisados e explicados em diferentes abordagens teóricas nos artigos encontrados;

c) analisar as proposições apresentadas com a finalidade de entendimento da temática selecionada;

d) identificar nos trabalhos levantados como tem sido abordada a questão da formação inicial e contínua de professores no que diz respeito ao tema da inclusão escolar.

\section{RESULTADOS}

A predominância dentro desses artigos pesquisados - no recorte temporal de 2005 a 2015 foi a área de educação especial e psicologia.

No período situado entre 2005 e 2015, identificamos 38 artigos que retrataram a temática aqui exposta.

No artigo intitulado "Processo de inclusão na escola regular: panorama de percepções", Furini (2006) ressalta que é necessário fazer modificações no currículo, na didática, nos conteúdos, na formação docente, pois a criança com TEA necessita ser avaliada de forma significativa. Segundo Mittler (2003), a avaliação pode facilmente se tornar um instrumento de exclusão social caso desconsidere-se as singularidades de cada criança. Assim, é importante que as escolas desenvolvam políticas e práticas de avaliações diferenciadas.

Rodrigues e Spencer (2010, p. 101) afirmam que:

Não há como falar em inclusão sem mencionar o papel do professor. É necessário que ele tenha condições de trabalhar com a inclusão e na inclusão. Será infrutífero para o educador aprender sobre dificuldades de aprendizagem e modos de intervenção psicopedagógica se não conseguir incluir o aluno.

Diante do assinalado, o professor tem papel importante na inclusão da criança com TEA. O referido necessita de uma formação constante que proporcione atividades adequadas e significativas para o sucesso no processo de ensino e de aprendizagem escolar dessas crianças. As pesquisas realizadas no período analisado evidenciaram a importância da formação docente no campo das políticas inclusivas. 
No que se refere às populações investigadas, o levantamento bibliográfico apontou a predominância de pesquisas realizadas nos anos iniciais do ensino fundamental de escolas públicas.

É importante pensar na formação inicial e continuada dos docentes para que as leis de inclusão sejam efetivas na sala de aula, para que cada criança seja tratada em sua singularidade, sendo ofertado um ensino de qualidade com metodologias de ensino que contribuam para o desenvolvimento das potencialidades de cada estudante.

\section{DISCUSSÃO}

O termo "autismo" é oriundo da palavra grega "autos" que significa "próprio" ou "de si mesmo" A partir de 1943, Kanner começa a delimitar o estudo científico do autismo.

Segundo Almeida (2005), a palavra autismo vem do grego "autos", que significa "eu próprio", referindo-se a alguém retraído e absorto em si mesmo. Retomando uma consideração histórica sobre o surgimento do autismo, encontraremos em Eugen Bleuler (1857 - 1939) a utilização pela primeira vez do referido termo.

De acordo com a primeira descrição do autismo feita por Kanner em 1943, as características presentes no autista são: incapacidade para desenvolver relações com outros indivíduos, atraso na aquisição da linguagem, uso não comunicativo da linguagem verbal, ecolalia, jogo repetitivo e estereotipado, boa memória de repetição e aparência física normal.

A partir do exposto, ressaltamos a importância da formação docente para a inclusão escolar, levando em consideração que o princípio fundamental da escola inclusiva é o de que todas as crianças possam aprender, sempre que possível, independentemente de quaisquer dificuldades ou diferenças que elas possam ter.

O desenvolvimento de escolas inclusivas que ofereçam serviços a uma grande variedade de alunos em ambas as áreas rurais e urbanas requer a articulação de uma política clara e forte de inclusão junto com provisão financeira adequada - um esforço eficaz de informação pública para combater o preconceito e criar atitudes informadas e positivas um programa extensivo de orientação e treinamento profissional - e a provisão de serviços de apoio necessários. Mudanças em todos os seguintes aspectos da escolarização, assim como em muitos outros, são necessárias para a contribuição de escolas inclusivas bem-sucedidas: currículo, prédios, organização escolar, pedagogia, avaliação, pessoal, filosofia da escola e atividades extra-curriculares. (UNESCO, 1994, p. 8).

Qualquer escola que se propõe a trabalhar em uma perspectiva inclusiva, deve articular recursos financeiros e uma política eficiente de inclusão que tenha como princípio erradicar o preconceito. É necessário também investir em aspectos como formação continuada para seus profissionais, currículo, avaliação e estrutura física com acessibilidade.

A LDBEN 9394/96, em seu artigo 59, assegura aos educandos com necessidades educacionais especiais um currículo adaptado às suas necessidades específicas. Em virtude de suas deficiências, necessitam de uma integração significativa, professores com especialização adequada e capacitados para trabalhar com esse público em classe comum e acesso ao conhecimento científico de forma significativa, aponta Furini (2006).

No artigo "Projeto político pedagógico e inclusão escolar: um diálogo possível", do autor Rogério Drago, pode-se notar que, quando falamos de inclusão escolar de pessoas com deficiência, infelizmente ainda nos causa insegurança, pois a maioria dos profissionais não estão preparados para lidar com essa situação, como apresenta o artigo: "A importância da pedagogia nos processos inclusivos" (2014) que buscou problematizar os processos inclusivos nos ambientes educativos. Quem traz o debate são as professoras Doutoras do Rio Grande do Sul, Morgana Domênica Hattge e Viviane Klaus. As referidas trazem à discussão o fato de que a Pedagogia tem se silenciado e submetido ao saber clínico ou da área psi e não tem cumprido a sua função na produção de práticas pedagógicas que atendam às necessidades específicas dos sujeitos. 


\section{CONCLUSÃO}

Diante da pesquisa realizada, observamos que a criança autista tem possibilidades de desenvolver-se e aprender, apesar de suas limitações como qualquer ser humano. É preciso que o docente conheça as características da criança autista, para que assim possa buscar estratégias para auxiliar na construção do conhecimento e o melhor caminho para se chegar à autonomia.

É de extrema importância lembrar que a criança autista, para ter sucesso no seu processo de ensino e aprendizagem deve ser aceito por todos, estimulada, tratada com equidade. E o professor exerce um papel fundamental junto à família como mediadores de sua aprendizagem.

As propostas pedagógicas na perspectiva da educação inclusiva preveem que as políticas educacionais devem estar articuladas com a prática escolar para que ocorra o processo de aprendizagem e que o desenvolvimento do aluno aconteça (BRASIL, 2007).

No artigo "As bases do processo de formação docente voltado à inclusão", Piccolo (2009) buscou demonstrar uma nova maneira de pensar na formação de professores em uma perspectiva inclusiva.

Para finalizar, citamos Xavier (2002, p. 19).

A construção da competência do professor para responder com qualidade às necessidades educacionais especiais de seus alunos em uma escola inclusiva, pela mediação da ética, responde à necessidade social e histórica de superação das práticas pedagógicas que discriminam, segregam e excluem, e, ao mesmo tempo, configura, na ação educativa, o vetor de transformação social para a equidade, a solidariedade, a cidadania.

\section{REFERÊNCIAS}

ALMEIDA, A. L. de. (2005) Interação de crianças autistas com o mundo digital: uma travessia de emoção e prazer. Florianópolis: UFSC/PPGEP. 263p.

BRASIL. Declaração de Salamanca e Linha de Ação Sobre Necessidades Educacionais Especiais. Brasília: Corde, 1994.

BRASIL. Ministério da Educação. Plano de Desenvolvimento da Educação: razões, princípios e programas. Brasília: MEC, 2007.

FONSECA, J. J. S. Metodologia da pesquisa científica. Fortaleza: UECE, 2002. (Apostila) disponível em: http://www.ia.ufrrj.br/ppgea/conteudo/conteudo-20121/1SF/Sandra/apostilaMetodologia.pdf(Acesso em 20 de novembro de 2016).

FRAZÃO, S. PORTO, L. Integração em educação especial: Questão de concepção ou de instituição. Revista Espaço. Rio de Janeiro:1999, p. 65-68.

FURINI, A. B. Processo de inclusão na escola regular: panorama de percepções. Cadernos em pesquisa de educação, n. 28, 2006. Disponível em: http://periodicos.ufes.br Acesso em: 01 jul. 2017.

HATTGE, M. D.; KLAUS, V. A importância da pedagogia nos processos inclusivos. Revista educação especial, Santa Maria, v. 27, n. 49, p. 327-340, 2014 . Disponível em: http://www.ufsm.br/revistaeducacaoespecial. Acesso em 26 jun. 2017. Acesso em 18 jun. 2017.

MANTOAN, M.T.E. (1997) Ser ou Estar, eis a questão: explicando o déficit intelectual. Rio de Janeiro: WVA.

MITTLER, P. Educação Inclusiva: contextos sociais. Porto Alegre: Artes Médicas, 2003. 
PICCOLO, G. M. As bases do processo de formação docente voltado à inclusão. Revista educação especial, Santa Maria, v. 22, n. 35, p. 363-374, 2009. Disponível em : http://www.ufsm.br/revistaeducacaoespecial. Acesso em 22jun.2017.

RODRIGUES, J. M. C.; SPENCER, E. A criança autista: um estudo psicopedagógico. Rio de janeiro: Wak, 2010.

SALGADO, A. M. (2012). Impasses e passos na inclusão escolar de crianças autistas e psicóticas: o trabalho do professor e o olhar para o sujeito. Dissertação de mestrado, Universidade Federal do Paraná, Curitiba, PR, Brasil.

XAVIER, Alexandre Guedes Pereira. Ética, técnica e política: a competência docente na proposta inclusiva. In: Revista integração, ano 14, no 24. Brasília: Ministério da Educação/ Secretaria de Educação Especial, 2002. 